\title{
BENTUK TARI MEGATRUH KARYA DARYONO
}

\author{
Mutiara Nabiella \\ Institut Seni Indonesia (ISI) Surakarta \\ Jalan Ki Hadjar Dewantara No.19, Kentingan, Jebres, Surakarta 57126 \\ Pramutomo \\ Institut Seni Indonesia (ISI) Surakarta
}

\begin{abstract}
Abstrak
The Megatruh dance is one of the traditional dance performed by a single man based on contemporary style, created by Daryono. This is one of the works which is applied Surakarta style (Kasunanan and Mangkunagaran) and Yogyakarta. This work was born from a creativity possessed by Daryono, enriched by many improvised patterns in the performance. Therefore, it can be concluded from this study that the objective of the study was to examine the form and development of creative elements in the Megatruh dance. Studying the problem of the dance's form used the concept of Alma M. Hawkins which was highlighted by Suzane K. Langer's thought. Meanwhile, to discuss the problem of developing the creative elements, this study used the concept of Sandra Cerny Minton. The writing process and review of the study used qualitative methods with descriptive analysis models to explain the form. The results of this study was that the form of this work is a structured improvisation carried out directly on the stage. It was totally relied on how Daryono used his body and applied his dance experience on his work, Megatruh Dance.
\end{abstract}

Keywords: Megatruh Dance, Development of Creative Elements, Forms.

\section{PENDAHULUAN}

Tari Megatruh merupakan salah satu karya tari putra tunggal menggunakangaya tradisi berbasis kontemporer yang disusun oleh Daryono. Tari Megatruh adalah karya tariberangkat dari jenis tembang macapat yang terdiri dari Mijil, Dandhanggula, Megatruh, Pocung, Durma, Kinanthi. Tembang tersebut mengilhami khususnya dalam penyusunan gendhing. Tari inilebih dominan menggunakan gendhing Megatruh meskipun ada sulukan yang bukan Megatruh. Hal ini membuat gendhing Megatruh menjadi sangat kental dalam penyusunan karya tari ini.
Tari digarap dalam bentuk putra tunggal yang tidak mengambil dari wiracarita. Wiracarita adalah cerita yang memfokuskan pada kepahlawanan, yang lebih banyak terdapat nilai-nilai berkaitan dengan hal jahat dan hal baik. Contoh dari cerita tersebut yang sering dijumpai yaitu cerita Ramayana dan Mahabarata (Wahyu Santosa Prabowo, wawancara 18 Juli 2019). Eksplorasi gerak tari Megatruh tidak terbatas. Tari tunggal yang vokabuler geraknya diambil dari ragam gerak tari alus dan gagah, dengan gaya Surakarta (Kasunanan dan Mangkunagaran) serta Yogyakarta. Gerak-gerak yang digunakan digarap kembali dan dikembangkan serta 
disesuaikan dengan kebutuhan karya tari ini. Tari Megatruh dalam menarikannya olah rasa dan pengenalan tubuh sangat dibutuhkan. Tubuh penari dalam tari ini merupakan sumber dari gerak sekaligus media ekspresi yang secara visual digunakan sebagai alat komunikasi, guna mengungkap pesan yang ingin dikomunikasikan dalam diri penari. Tari Megatruh dalam menarikannya juga membutuhkan ketenangan, konsentrasi dan kepekaan terhadap gendhing (Daryono, wawancara 3 Desember 2018).

Arti nama Megatruh atau Megatruh oleh sebagian orang diartikan sebagai putusnya tubuh rohani dengan tubuh jasmani sehingga manusia tidak berjiwa lagi alias mati wadag, atau badan rusak. Perginya tubuh rohani, ruh, dari jasad rusak, akan mencari tempat paling tepat bagi dirinya. Setelah kita tahu medium pokok pada tari adalah gerak tubuh manusia dan tidak luput menggunakan media pendukung yaitu karawitan tari dan Instrument gamelan yang dimainkan karya ini ialah gender, kemanak, dodogan, keprak, dan gong kemodhong.

Berdasarkan informasi yang didapat tari Megatruh berangkat dari potensi dan kompetensi yang dimiliki oleh penyusun, sehingga dengan daya interpertasi dan pengalaman yang cukup baik maka terciptalah sebuah karya tari yang berbeda dengan karya tari pada umumnya. Karya tari yang berangkat dari pengalaman setiap penari yang menarikannya. Sebagai penyusun dan penari tari Megatruh, Daryono memiliki kemapanan gerak atau tafsir pelaksanaan gerak terhadap rasa dan kepekaan rasa gerak dengan iringan maupun tembang yang ada di dalamnya. Dua hal tersebut dijadikan bagian terpenting dan mendorong untuk pencapaian rasa disertai pengungkapannya melalui gerak. Daryono dalam menarikan tari ini membutuhkan konsentrasi tinggi, mengingat dalam karya tari ini tidak pernah melalui adanya latihan antara penari dan karawitan tari. Karya tari ini merupakan tari yang berangkat dari improvisasi dan kemapanan yang dimiliki.

\section{PEMBAHASAN \\ Bentuk Tari Megatruh}

Penyusun sekaligus penari dalam tari Megatruh adalah Daryono, merupakan salah satu tokoh tari tradisi Surakarta. Pria kelahiran Wonogiri, 11 November 1958 adalah seorang Penari, Koreografer, Dosen Tari di Institut Seni Indonesia Surakarta. Daryono sempat beberapa tahun mengajar di Pascasarjana Institut Seni Indonesia Surakarta. Daryono merupakan seorang penari senior yang masih aktif di Mangkunagaran.

Setelah diteliti lebih lanjut, Daryono yang dikenal oleh orang sekitar adalah seorang penari alus, ternyata sangat berbeda dengan kenyataan yang terjadi. Bahwa sebenarnya Daryono lebih tertarik dan menguasai dalam tari gagah menurutnya lebih terlihat bersemangat, lincah dan tampak greget. Terlihat dari karya-karya Daryono yang rata-rata menggunakan madya, di samping menggunakan ragam gerak gagah tetapi tidak lupa menggunakan alus.

\section{Megatruh Sebagai Karya Unggulan Daryono}

Tari Megatruh diciptakan Daryono pada tahun 2007, tari ini digarap dalam bentuk tari tunggal putra. Tari ini 
merupakan salah satu karya tari yang menjadi karya unggulan Daryono dalam kiprahnya di dunia seni tari. Mengapa disebut unggulan, salah satu keunikannya tampak pada bentuk sajian yang menggabungkan karakter gerak kualitas gagah dan alus. Tari ini berisi bagaimana ketubuhan Daryono serta dalam tari ini merupakan hasil improvisasi Daryono diatas panggung. Sebelumnya dalam menampilkan karya ini tidak ada latihan dengan karawitan tari. Pernyataan bahwa Megatruh adalah tari unggulan Daryono di benarkan oleh Wahyu Santoso Prabowo karena dalam tari Megatruh prosesnya sangat intens. Daryono sendiri selalu menemukan hal baru dalam berkesenian, artinya selalu muncul kreativitas yang baru. Megatruh merupakan hasil dari kiprahnya berkesenian, maka sangat sepakat apabila Megatruh adalah karya unggulan yang dimiliki Daryono (Wahyo Santoso Prabowo, wawancara 21 Januari 2019). Pencarian karya Megatruh cukup lama, Megatruh ini seperti karya besar yang dimiliki Daryono karena beberapa kali tari ini ditampilkan dengan orang berbeda, terasa berbeda juga hasilnya hasilnya (Mauritius Tamdaru wawancara 22 September 2019).

Eksplorasi gerak tari dalam karya ini tidak terbatas pada tari gaya Mangkunagaran saja, tetapi juga gaya Kasunanan Surakarta dan Yogyakarta. Daryono berusaha untuk mewujudkan bentuk tari dengan kualitas baru. Selain itu, karya tari ini menggambarkan bagaimana perjalanan hidup dan kepenarian Daryono. Perjalanan kepenariannya karya ini satusatu nya karya Daryono yang tidak mempunyai pakem-pakem atau patokan tertentu. Pada suatu hari saat diskusi Daryono membenarkan bahwa adanya "pelepasan" yang artinya melepaskan semua normanorma yang mengikat terdapat dalam tubuh. Pelepasan yang dimaksud meliputi norma bentuk, gerak. Daryono saat menari dapat melepaskan semua itu. Menurut Daryono ini adalah sebuah cara bagaimana melihat kembali lewat eksplorasi yang total. Setelah melepas tapi justru Daryono memperhatikan kembali perabot yang dia punya. Perabot yang dimaksud adalah kemampuan kepenariannya yang sudah dia dapatkan sampai saat ini yaitu teknikteknik yang ada dalam tubuh. Seakanakan di luar semua itu Daryono seperti melihat tubuhnya kembali. Mengapa dikatakan karya unggulan karena memang dalam karya tari ini kemampuan ketubuhan penari sangat menjadi pokok utama dalam proses pembentukan motif gerak tari Megatruh. Semua itu dapat dilihat berdasarkan kualitas kepenarian, pengalaman dan energi.

\section{Tinjauan Bentuk Tari Megatruh}

Pengamatan dalam suatu karya tidak lepas dari bentuk sajian yang meliputi struktur, artikulasi, dan hasil dari kesatuan berbagai faktor yang saling berganyutan. Hal tersebut digunakan untuk menguraikan bentuk tari Megatruh. Komponen yang dapat diteliti dalam tari ini antara lain: gerak, busana, rias, pola lantai, karawitan tari.

\section{Gerak}

Gerak tari yang diterapkan pada tari Megatruh tidak selalu dilaksanakan dalam tempo yang cukup lamban melainkan dipadukan dengan tempo cepat, tidak mengikuti irama gendhing melainkan terlihat sangat kontras dengan alunan 
gendhing yang di tampilkan. Akan tetapi meskipun yang dilakukan oleh penari, yaitu sangat betolak belakang dengan tempo gendhing, penonton dapat menikmati menyatunya antara penari dan musik tari.

Pembentukan suasana dalam tari Megatruh pada dasarnya tergantung pada kemampuan kreativitas seniman ketika menyajikan tari tersebut. Ekspresi tarian akan lebih hidup dan tersampaikan apabila didukung dengan "rasa jiwa" dalam diri penari yang menyatu dengan tarian tersebut. Daryono, pada karya ini sangat membebaskan para penonton untuk mengapresiasi karya tersebut dengan imajinasinya masing-masing. Sehingga, menurut Daryono supaya tidak terjadi menggurui atau saling ngajari (Daryono, wawancara 3 Desember 2018).

Eksplorasi gerak pada tari Megatruh sendiri tidak terbatas. Tidak terbatas dalam artian tidak tertuju hanya pada satu ragam gerak dan gaya. Tari garap tunggal ini menggunakan ragam gerak tari alus dan gagah, dengan gaya Surakarta (Kasunanan dan Mangkunagaran) dan gaya Yogyakarta. Tari ini dalam kategori menggunakan jenis gerak madya, dan karya tari ini disusun tidak seperti yang sudah ada melainkan dikembangkan dan disesuaikan dengan menggarap sesuai kebutuhan. Artinya, karya ini disajikan sesuai kebutuhan karya itu saat akan dipertunjukkan. Daryono menggunakan penerapan meruang pada saat menari, entah dari arah hadap badan maupun geraknya.

Adeg untuk kriteria menarikan karya tari ini yaitu, seorang penari harus mampu flexible artinya, tubuhnya mampu berkualitas alus, gagah dan sedang (madya). Itu menjadi bagian yang sangat penting dalam menarikan karya ini, selanjutnya yaitu perlu diketahui juga bahwa karya tari ini tidak bisa ditampilkan oleh penari yang hanya mampu menarikan ragam gerak alus saja atau gagah saja. Penari diharuskan dapat menguasai kedua ragam gerak tersebut dan tidak hanya mampu salah satunya saja. Selanjutnya adalah pacak diuraikan dalam kebutuhan karya ini bahwa penari harus jelas pacaknya, yaitu bagaimana membawakan pacak alus dan bagaimana saat memasuki pacak gagah. Disitu penari diharapkan jelas dalam perbedaannya. Penari dapat " $u t u h$ ", dalam artian mampu melakukan gerak dengan jelas contohnya, melakukan tanjak dengan baik yaitu suatu ketentuan dalam tari alus dan gagah. Selanjutnya yang terakhir yaitu gerak yang benar atau solahe pener, benar dalam artian mana bagian tubuh yang digerakkan itu terlihat jelas.

\section{Busana}

Busana dalam tari mempunyai fungsi untuk mendukung tema atau isi dan memperjelas peranan-peranan dalam suatu sajian tari. Tari Megatruh perwujudannya tidak lepas dari peran busana. Seperti halnya di dalam karya tari ini tidak lepas dan mengacu pada gerak-gerak tradisi. Pada umumnya busana merupakan sarana pendukung yang mempunyai peran penting dalam keberhasilan suatu pertunjukan tari. Karya tari ini menggunakan pola busana putra.

\section{Rias}

Rias adalah menata atau menghias yang medianya yaitu bagian wajah. Diperbaiki agar terlihat lebih baik, karena 
setiap wajah mempunyai karakter berbeda. Tinggal tujuan dari rias itu sendiri agar terlihat indah atau penegasan karakter (Dewi Kristiani, 18 Juli 2019). Rias yang digunakan dalam tari Megatruh ialah rias korektif. Rias korektif yang digunakan untuk mengkoreksi kekurangan yang ada pada wajah, penegasan dan ketajaman bentuk mata, alis dll.

\section{Karawitan Tari}

Tari Megatruh yang difokuskan pertunjukan ini ialah tari dan karawitan nya karena memang sangat dibutuhkan penyatuan antara penari dan karawitan agar saling mendukung, setting panggung dalam pementasan pun set gamelan dan karawitan tari berada di atas stage, karena memang ingin di fokuskan pada kedua nya dan ingin menunjukkan bahwa ini adalah pertunjukan tari dan musik. Terdapat dalam karya tari ini, tembang Megatruh mengilhami khususnya dalam penyusunan gendhing. Megatruh, yang artinya adalah mati wadag atau bisa dikatakan pada bagian manusia itu sudah mulai memisahkan diri antara ruh dan raganya. Tembang macapatan sendiri sudah ada urutannya mengenai kehidupan manusia.

Diartikan bahwa merefleksikan siklus kehidupan manusia dari mulai tembang Maskumambang dalam hidup diartikan "mengambang" atau menggambarkan bayi yang ada di dalam kandungan. Kedua tembang Mijil yang artinya "mbrojol" yaitu bayi lahir ke dunia. Ketiga tembang Sinom berarti "kanoman" atau penggambaran usia muda yang masih menginjak remaja. Keempat tembang Kinanthi yaitu "kanthi" yang artinya menggandeng atau bisa di ibaratkan tuntunan untuk menggapai masa depan.
Kelima tembang Asmarandhana yang berarti "kasmaran", di saat ini lah manusia mengerti akan dimabuk asmara. Keenam tembang Gambuh "cocok" artinya kecocokan dan kesiapan untuk membina rumah tangga. Ketujuh tembang Dhandhanggula yang artinya "keturutan" atau keberhasilan alam membina rumah tangga. Kedelapan tembang Durma "loma" atau dermawan, senang memberi karena rasa syukur kepada Tuhan. Kesembilan tembang Pangkur yang artinya "mungkur" atau bisa disebut menjauhi dari hal-hal negative. Kesepuluh ini yang menjadi judul dalam karya tari ini yaitu tembang Megatruh "megat ruh" terlepasnya ruh dengan raga nya atau mati. Terakhir yaitu tembang Pocung "pocong" yang artinya sudah dibungkus dan siap dikuburkan. Semua adalah refleksi dari siklus urutan kehidupan menurut tembang (Wahyu Santoso Prabowo, wawancara 21 januari 2019).

Tembang Megatruh dalam sajian musiknya dibungkus kedalam iringan disebut Ketawang Megatruh akan tetapi di dalam tembang nya tetap menggunakan tembang Megatruh dasar dari musik tari Megatruh hanya satu yang kebetulan menyesuaikan judul dari tarian nya yaitu menggunakan gendhing Megatruh merupakan salah satu repertoar tembang tradisi yang dilantunkan bergantian dengan kualitas dan variasi warna suara vokal lakilaki dan perempuan, dimaksudkan untuk membangun suasana. Porsi garapanya bermacam-macam, divariasi yang artinya satu gendhing Megatruh itu digarap menjadi berbagai versi yaitu dalam bentuk macapat, pathetan, ada- ada dan gendhing itu sendiri yaitu ketawang Megatruh. Tembangan dipilih untuk mewakili judul tari tersebut 
dalam syair-syairnya kurang lebih terdapat 8 tembang Megatruh.

Tari Megatruh sendiri menggunakan ricikan gamelan yang sangat minimal, terlebih dulu saat karya ini pertama kali dipentaskan hanya menggunakan gender saja sebagai alat musik sebagai penggiring.

Berkembangnya ide oleh Lumbini yang menjadi pengrawit sekaligus penyusun karawitan tari dalam karya ini, adanya perkembangan dan tentu sangat di setujui oleh Daryono selaku penyusun karya tersebut. Karena memang dibutuhkan sebagai tanda pergantian komposisi dan rasa seleh gerak pada sabetan gendhing sehingga geraknya agar lebih mantap. Akhirnya dalam pertunjukan yang di selenggarakan di Balai Soedjatmoko menggunakan tambahan yaitu gong kemodhong, kemanak dan perkembangan sampai disitu. Sesuatu yang menjadi daya tarik bagi penikmat adalah ke mistis an tidak saja di timbulkan saat kemanak terdengar, akan tetapi saat gender pertama kali di tabuh oleh Sumiyati atau biasa di panggil Mbah Kris yang memang sudah berkolaborasi dengan karya ini sejak tersusun. Sehingga adanya komunikasi batin atau kemistri yang terjalin anatara penari dan pemusik. Keprak adalah ricikan yang mempunyai peran untuk mempertegas irama sebagai koordinator tari dan karawitan. Lumbini, yang membantu dalam proses terciptanya susunan karawitan tari sekaligus anak dari Mbah Kris. Lumbini berpendapat bahwa dalam pertunjukan tersebut apabila hanya menggunakan gender saja belum mewakili, itu semua di terima oleh Daryono.

\section{Gagasan Utama}

Gagasan utama terciptanya tari Megatruh yaitu pada tahun 80an, baru pertama kali Daryono menyusun sebuah karya yang berjudul Pitutur. Karya tersebut Daryono menjadi tokoh, sejak itu mulai dirintis dan sudah di "syah" kan atau diakui keberadaan karya tersebut di ASKI meskipun tidak secara langsung. Setelah itu Daryono bersama temannya menciptakan drama tari yang berjudul "Ronggolawe Gugur", saat itu Daryono dan Sri Hadi ,menjadi pengapit Sinduro yang saat itu di perankan oleh Wahyu Santoso Prabowo. Bertiga, dalam adegan waktu itu Wahyu Santoso Prabowo menggunakan vokal, setelah Wahyu Santoso Prabowo mnyelesaikan adegannya, tinggallah Daryo dan Sri Hadi di atas panggung. Daryono dan Sri Hadi saat itu merasa tidak eksis dengan gerak-gerak alus. Lalu Daryo mengubah gerak-gerak alus itu menjadi gagah. Saat itu juga, setelah pementasan itu berlangsung tidak ada teguran dari siapapun termasuk Gendhon Humardhani. Sejak itu Daryo berfikir bahwa tidak ada masalah dalam perpaduan yang Daryo gunakan saat di atas panggung. Dari situlah seperti menjadi batu loncatan atau tonggak pertama dirinya untuk menciptakan tari Megatruh. Bisa disimpulkan bahwa dorongan tari Megatruh berawal dari terciptanya karya Pitutur dan Ronggolawe Gugur. Dari situ lah mendorong Daryono menciptakan tari Megatruh. (Daryono, wawancara 03-12-2018)

\section{PENUTUP}

Tari Megatruh merupakan sebuah karya tari tradisi berbasis kontemporer yang diciptakan pada tahun 2007 oleh Daryono. Karya ini terilhami oleh tembang 
Megatruh khususnya dalam iringannya. Arti nama Megatruh diartikan sebagai putusnya tubuh rohani dengan tubuh jasmani sehingga manusia tidak berjiwa lagi alias mati wadag, atau badan rusak. Tari putra tunggal yang tidak mengambil dari wiracarita ini menggunakan vokabuler gerak tari gagah dan alus, dengan gaya Surakarta (Kasunanan dan Mangkunagaran) dan Yogyakarta. Struktur karya tari ini secara garis besar terbagi menjadi maju beksan, beksan dan mundur beksan.

Musik yang digunakan adalah gamelan jawa yang terdiri dari gender, kemanak, dodogan, keprak, dan gong kemodhong. Adapun struktur sajian beksan dalam gendhing dapat di bagi yaitu maju beksan dari mulai grimingan sampai kendhangan macapat, lalu beksan dari mulai masuk kemanak dilanjut ada-ada lalu sampai pada gendhing Megatruh, selesainya gendhing Megatruh berarti selesainya juga dalam beksan, dilanjutkan yaitu mundur beksan mulai dari pathetan langsung dengan genderan gawan Kodhok Ngorek.

Rias yang digunakan hanyalah bedak tipis saja, karena menurut Daryono kali ini rias tidak lah sesuatu hal yang harus digunakan pada karya ini. Jika tidak memakai rias pun tidak masalah, karena hanya untuk pelengkap saja. Kostum yang selalu digunakan yaitu menggenakan jarik cancut dengan alasan agar dalam bergerak lebih leluasa. Selain itu untuk bagian atas selalu berubah, akantetapi pada saat pementasan di Balai Daryono memilih untuk ngligo.

Penyusun sekaligus penari dalam tari Megatruh adalah Daryono, merupakan salah satu tokoh tari tradisi Surakarta. Bentuk dari karya ini berwujud improvisasi yang dilakukan Daryono, karena memang dalam bebrapa kali dipentaskan tidak ada latihan dengan karawitan tari sebelumnya. Karya tari ini menggunakan gerak Madya yaitu campuran gagah dan alus.

Karya tari ini berisi bagaimana ungkapan ekspresi jiwa, emosi, pengalaman rohani dan ragawi, dengan kata lain kembali mengulang pengalaman hidup yang sudah di alami oleh penyusun melalui tubuhnya. Maka dari itu, setiap karya tari ini dipentaskan dengan orang yang berbeda akan berbeda pula bentuknya, tergantung konsep apa yang digunakan pada penari tersebut. Daryono membebaskan diri untuk bergerak mengikuti kata hati dan suasana hatinya dengan mengulang kembali memori perjalanan hidup yang sudah terjadi, melalui gerak serta mengandalkan kemampuan kepenariannya. Daryono menggungkapkan bahwa tema karya tari Megatruh sendiri adalah tentang ketubuhan dalam konteks kepenarian yang dimiliki.

\section{DAFTAR PUSTAKA}

Aro, Tri. Jurnal Kesenian Pohon Hayat dengan judul " Memaknakan Kembali Budaya Dalam Seni “ vol 1-no 1: 2009.

Djelantik, A. M. 1992. Pengantar Dasar Ilmu Estetika Jilid 1 Falsafah Keindahan dan Kesenian. Denpasar: Sekolah Tinggi Seni Indonesia Denpasar.

Hadi, Sumandyo. 2007. Kajian Tari Teks dan Kontekstual. Yogyakarta: Pustaka Book Publisher.

Hawkins, Alma M. 2003. Bergerak Menurut Kata Hati. Terj. I Wayan Dibia. Jakarta 
: Ford Foundation dan Masyarakat Seni Pertunjukan Indonesia.

Langer, Suzanne K. 1988. Problematika Seni.

Bandung: ASKI Bandung. Maryani,

Dwi. Bentuk Sajian Tari Srikandhi

Cakil. Jurnal Gelar. Vol 8, 2010.

Murgiyanto, Sal. 1983. Koreografi. Jakarta: Departemen Pendikan dan Kebudayaan.

Minton,Cerny Sandra. 1997 CHOREOGRAPHY ; A Basic Approach Using Improvisation (Second Edition Greenley ; University of Northern Colorado, 1997).

Moleong, Lexy, J. 2008. “Metodologi Penelitian Kualitatif". Bandung: Remaja Rosdakarya.

Pujiyanti. Jurnal Gelar. 2007. "Analisis Koreografi Tari Srikandi Bisma".

Purwanto. Heru. 2011. "Megatruh" dan "Ruming Mulad" Penyajian karya tari Tugas Akhir Kepenarian.

Supriyadi, Dedi. 1994. Kreativitas, Kebudayaan dan Perkembangan IPTEK. Jakarta: CV. Alfabeta.
Widyastutieningrum, Sri Rochana dan RM Pramutomo. 2007. Penulisan Kritik Tari. Pengembangan Ilmu Budaya: ISI Press Surakarta.

\section{NARASUMBER}

1. Daryono, (59 tahun), Tenaga pengajar di Institut Seni Indonesia Surakarta. Triyagan, Mojolaban Sukoharjo.

2. Lumbini Tri Hasto, (49), Panata Laboratorium Pendidikan di Institut Seni

3. Indonesia Surakarta. Sabrang Wetan, Jebres Surakarta. Heru Purwanto, (39), Penari Wayang Orang Sriwedari.

4. Wahyu Santoso Prabowo, (65), Seniman tari. Mojosongo Surakarta.

5. Mauritius Tamdaru, (25), Mahasiswa Pascasarjana Institut Seni Indonesia (ISI) Surakarta. Gambuhan Baluwarti.

6. R.M Pramutomo, (51), Dosen Institut Seni Indonesia (ISI) Surakarta 